\section{Leukoerythroblastisches Blutbild}

H. Baum

Institut für Laboratoriumsmedizin, Mikrobiologie und Blutdepot, Regionale Kliniken Holding RKH GmbH, Ludwigsburg, Deutschland

Englischer Begriff leucoerythroblastosis

Definition Nachweis von wenigen Blasten und Vorstufen der Erythropoese im peripheren Blut bei Osteomyelofibrose.

Beschreibung Im fibrotischen Stadium der Osteomyelofibrose kommt es zur extramedullären Blutbildung in der Leber und Milz sowie dem Auftreten von Blasten und kern- haltigen Vorstufen der Erythropoese im peripheren Blut. Dabei ist die Gesamtzellzahl meist normal oder nur leicht erhöht, der Blastenanteil $<10 \%$ bei einer gleichzeitigen Anämie sowie Poikilozytose ( $\triangleright$ Poikilozyten) der Erythrozyten mit Dakrozyten. Im präfibrotischen Stadium der Erkrankung ist meist keine oder nur eine milde Leukoerythroblastose nachweisbar.

\section{Literatur}

Thiele J, Pierre R, Imbert M et al (2001) Chronic idiopathic myelofibrosis. In: Jaffe ES, Harris NL, Stein H et al (Hrsg) Pathology and genetics of tumors of haematopoietic and lymphoid tissues. IARC Press, Lyon, S 35-38 